University of Wollongong

Research Online

Faculty of Engineering - Papers (Archive)

Faculty of Engineering and Information

Sciences

$1-1-2011$

\title{
Analysis of microstructure effects on edge crack of thin strip during cold rolling
}

Haibo Xie

hx899@uow.edu.au

Zhengyi Jiang

University of Wollongong, jiang@uow.edu.au

W Y Daniel Yuen

Follow this and additional works at: https://ro.uow.edu.au/engpapers

Part of the Engineering Commons

https://ro.uow.edu.au/engpapers/3173

\section{Recommended Citation}

Xie, Haibo; Jiang, Zhengyi; and Yuen, W Y Daniel: Analysis of microstructure effects on edge crack of thin strip during cold rolling 2011, 1244-1252.

https://ro.uow.edu.au/engpapers/3173

Research Online is the open access institutional repository for the University of Wollongong. For further information contact the UOW Library: research-pubs@uow.edu.au 


\title{
Analysis of Microstructure Effects on Edge Crack of Thin Strip During Cold Rolling
}

\author{
HAIBO XIE, ZHENGYI JIANG, and W.Y. DANIEL YUEN
}

Edge cracks in cold rolling of the thin strip affect the strip quality and productivity significantly. In this study, an experimental and mechanical investigation on microstructures has been carried out to study the edge crack formation during cold rolling of the thin strip. The effects of the feed material microstructures on the edge crack evolution were studied employing optical microscopy and scanning electron microscopy (SEM). Experimental observation indicates that fine grain occurs in hot-rolled microstructure and coarse grain is produced in ferritic rolled microstructure. Different grain sizes affect significantly the formation mechanics of the microcrack, crack initiation, and orientation of crack extension. The grain size and grain boundaries effects on crack retardation are discussed also during edge crack initiation. During the crack growth in coarse grain, most edge crack tips will blunt, which improves the crack toughness by causing less stress concentration. Overall, the fine microstructure shows a good crack initiation resistance, whereas the coarse microstructure has a better resistance to crack propagation. This research provides additional understanding of the mechanism of microstructure influence on edge crack evolution of cold strip rolling, which could be helpful for developing defect-free thin strip.

DOI: $10.1007 / \mathrm{s} 11663-011-9540-3$

(C) The Minerals, Metals \& Materials Society and ASM International 2011

\section{INTRODUCTION}

Metals tend to develop edge cracks during hot and cold rolling occasionally. Cracks in metal products decrease the strength, rigidity, toughness, plasticity, and residual life, which affect the thin strip quality and productivity significantly. The phenomenon of edge cracking in cold rolling of steel is complicated, depending on rolling conditions, as well as the microscopic factors such as the microstructure, inclusions, and pores. From the viewpoint of an engineer who is applying metal forming processes to the production line, it is important to define the fracture event because the ultimate stage of the rolled strip is preceded by or corresponds to crack initiation and propagation. Ductile fracture has been the subject of considerable interest by fracture mechanics researchers because of its practical engineering importance. Such interest has prompted the development of several ductile fracture criteria including notably crack opening displaces (CODs), and J-integral and strain-energy density. ${ }^{[1,2]}$ Before the cracks grow to a critical length in successive rolling passes, edge cracks need to be removed by a trimming operation to prevent the possible rupture of the sheet in the rolling mill. The

HAIBO XIE, Associate Research Fellow, and ZHENGYI JIANG, Professor, are with the School of Mechanical, Materials and Mechatronic Engineering, University of Wollongong, Wollongong, NSW 2522, Australia. Contact e-mail: hx899@uowmail.edu.au W.Y. DANIEL YUEN, Manager Research, is with the BlueScope Steel Research, BlueScope Steel Limited, Port Kembla, NSW 2505, Australia.

Manuscript submitted December 14, 2010.

Article published online June 28, 2011. situation becomes critical when the remaining width of the strip does not meet the requirement of the next stage of the process. Therefore, the microstructure factors that may influence the strip cracking must be investigated simultaneously with the evolution mechanism of edge cracks.

There are numerous publications about the research on cracks during metal forming. Physical defects are important factors that affect the material fracture strength. ${ }^{[3]}$ Damage mechanics and fracture models of ductile materials have been introduced into crack evolution analysis. ${ }^{[1,4,5]}$ Stored energies were applied to validate the damage mechanism, ${ }^{[6]}$ and void growth study was conducted for plasticity and ductile fracture damage. ${ }^{[7]}$ The research on crack initiation was carried out in steel, ${ }^{[8-10]}$ and phase transformation contributed to toughening around the crack tip. ${ }^{[1]}$ Previous studies showed that the fracture behavior of materials was influenced greatly by their microstructures. ${ }^{[12]}$ The surface and longitudinal cracks have been reported in continuous casting. ${ }^{[13,14]}$ Edge crack evolution during rolling was analyzed, ${ }^{[15-18]}$ and microstructure influences on crack formation were investigated also. ${ }^{[19,20]}$ Additionally, the influences of the grain size on crack initiation and crack growth were investigated. ${ }^{[21-23]}$ The fracture toughness of low-carbon steel is governed largely by the initiation and propagation characteristics of the microcracks generated at the crack tip. In lowcarbon steel, voids nucleate usually at pearlite and second-phase particles, and plastic deformation causes the voids to grow into microcracks. The edge crack will initiate when the void volume fracture reaches a critical value of around 3 pct. An equation for rate of void nucleation $^{[17]}$ is shown as follows, 


$$
\dot{f}_{\text {nuc }}=\frac{f_{N}}{\sqrt{2 \pi} S_{N}} \exp \left(-\frac{1}{2}\left(\frac{\varepsilon_{e}^{p l}-\varepsilon_{N}}{s_{N}}\right)^{2}\right) \dot{\varepsilon}_{e}^{p l}
$$

where $\varepsilon_{e}^{p l}$ is the equivalent plastic strain, $f_{N}$ is the total void volume fracture that can be generated by nucleation along the strip edge, $\varepsilon_{N}$ is the strain at which the nucleation rate is maximum, and $s_{N}$ is the width of the distribution function of strains over which voids nucleate.

Although it is known widely that microstructures, such as the grain sizes, have an important influence on material properties, this factor is usually not included in most analysis of deformation and crack evolution. Little research has been carried out about the effect of microstructure, especially under the ferritic rolling, on edge cracks of thin strip during cold rolling, particularly the effect of grain size, which has yet to be investigated. The ferritic rolling is situated between the cold and hot rolling, a low-cost method of producing thin strip products. The economical advantages related to the ferritic rolling are energy savings from a low reheating temperature, less oxidation in the reheating furnace, and no more metallurgical limitation for the rolling of very thin gauge strip. In this study, mechanics and experimental investigation were conducted to study the edge crack evolution relating to the initial microstructure during cold strip rolling and to characterize the crack initiation and crack propagation of various microstructures (coarse and fine grains) of the low-carbon steel. The primary causes for the cracking were analyzed with a detailed microstructure examination, and practical methods to prevent or minimize the cracking were generated based on the microstructural analysis of the cracking region.

\section{MATERIALS AND EXPERIMENTAL}

During the experimental procedure, several microstructures, such as the coarse and fine microstructures, were achieved under various rolling temperatures. The experimental material was plain low-carbon steel (C $0.06 \mathrm{wt}$ pct). Samples with different grain sizes were used to establish a relationship between the edge crack and microstructure, which were collected after hot and cold rolling experiments for further optical and SEM analysis. The steels were mounted, polished, and etched in a 2.5 pct natal solution, and the volume fractures of ferrite and pearlite were measured with an image analyzer.

To understand the effect of the rolled microstructure on the initiation and propagation of edge crack, physical simulation was conducted on the experimental mill to generate the samples with various microstructures. The rolling temperatures $[1023 \mathrm{~K}, 1048 \mathrm{~K}, 1083 \mathrm{~K}, 1133 \mathrm{~K}$, and $1173 \mathrm{~K} \quad\left(750{ }^{\circ} \mathrm{C}, 775^{\circ} \mathrm{C}, 810^{\circ} \mathrm{C}, 860{ }^{\circ} \mathrm{C}\right.$ and $900{ }^{\circ} \mathrm{C}$ )] were selected in such a way that the experiments fall within complete ferritic rolled microstructure or hot-rolled microstructure regions. The microstructure development during rolling in a single pass $(50$ pct or $60 \mathrm{pct})$ at five different temperatures was investigated. Cold rolling experiments were carried out on a four-high experimental rolling mill to identify the initiation and propagation of the edge cracks. The feeding strip is $50 \mathrm{~mm}$ wide with a thickness of approximately $2 \mathrm{~mm}$. A total of 10 passes was employed to achieve the overall reduction of the strip of more than $90 \mathrm{pct}$, whereas single pass reduction was approximately 30 pct.

\section{RESULTS AND ANALYSIS}

During cold rolling, cracks originated at the strip edges after critical deformation, which are undesirable not only because of the appearance of the surface but also its influence on the strength, formability, and other manufacturing characteristics.

\section{A. Rolled Microstructures}

The hot-rolled microstructures at the center and edge at $1173 \mathrm{~K}\left(900{ }^{\circ} \mathrm{C}\right)$ are shown in Figure 1(a). The ferritic grain was refined even more by more deformed stored energy. Furthermore, the complete recrystallizated austenite was transferred into fine ferrite under subsequent cooling. This microstructure is a typical hotrolled microstructure that contains equiaxed ferrite and lameller pearlite, and the grain size is approximately $9.5 \mu \mathrm{m}$ with the aspect of grain shape at approximately 1. Elongated ferritic grains with a mixture of a little equiaxed ferritic and pearlitic microstructure were formed during rolling at $1023 \mathrm{~K}\left(750^{\circ} \mathrm{C}\right)$ as shown in Figure 1(b), and it is typical ferritic rolled microstructure. The ferrite was deformed and underwent workhardening without significant recrystallization, and the ferritic grains transformed from a polygonal shape to an elongated shape. The average grain size is $15 \mu \mathrm{m}$, and an aspect of grain shape is approximately 0.75 . The grains are larger in the central region and smaller near the edge region due to the higher cooling rate in the edge region. The aspect ratio of elongated grains becomes larger as it moves from the center to the edge, resulting in a more elongated shape in the edge region.

Irrespective of the location, all microstructures are composed typically of ferrite and pearlite. Near the strip surface, several equiaxed grains are observed, and the number of elongated grains increases as it gets deeper into the interior. This effect is observed because dynamic recrystallization proceeds on the plate surface as the stored energy of the surface is higher than that of the interior because of the lower temperature and heavier rolling load on the surface.

\section{B. Effect of Microstructure on Edge Crack Initiation}

Both microstructures are parallel to the rolling direction in an elongated shape. According to SEM observation of the polished and etched samples, the most preferred site for crack nucleation in the rolled steel was found to be the edge pores. The resistance to fracture drops rapidly with porosity, and the fracture energy of porous materials decreases when the pore volume fraction exceeds a critical value. ${ }^{[20]}$ Void nucleation accelerates with strain accumulation at the strip edge (more reduction) during the rolling processing, as 

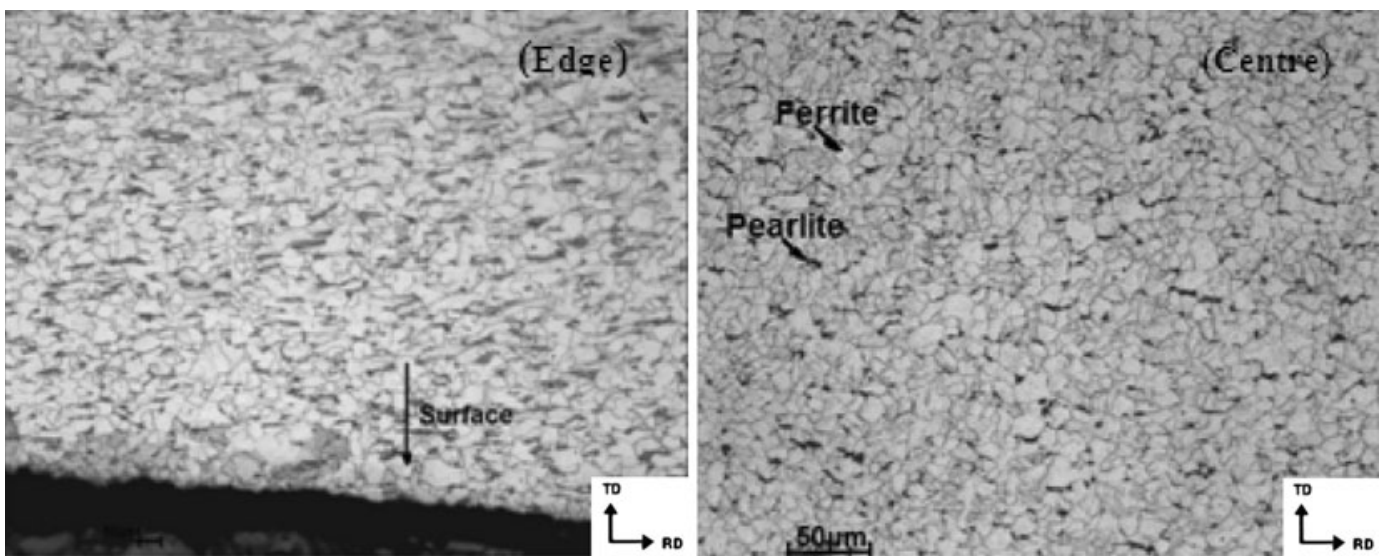

(a)
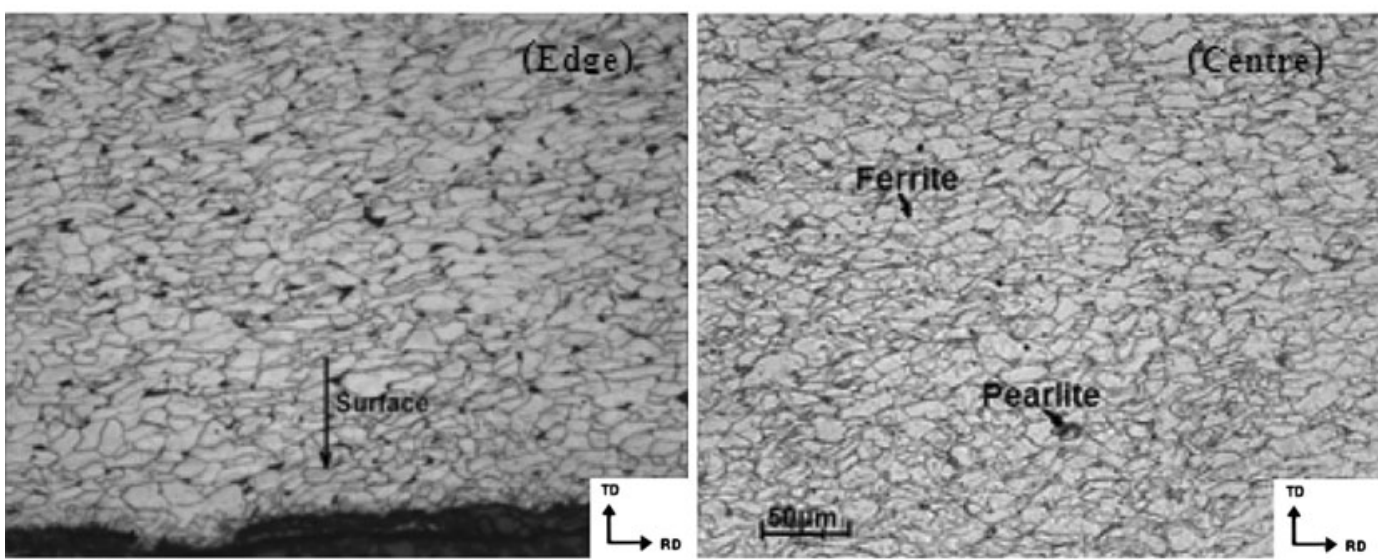

(b)

Fig. 1-(a) Hot-rolled microstructures and (b) ferritic rolled microstructures. TD: Transversal direction; RD: Rolling direction.

indicated in Eq. [1]. The initiation of most microcracks does not simply pass through the pores but spreads around them, causing the crack front to become curved because of the grain boundary barrier. The initiation of edge crack of different initial rolled microstructures is shown in Figure 2. Figure 2(a) is coarse grain and Figure 2(b) is fine grain. It can be observed that there are more microcracks in coarse grains than that in fine grains. The former is approximately 6 per $0.5 \mathrm{~mm}$, whereas the later is approximately 4 per $0.5 \mathrm{~mm}$. Various edge porosities are prone to change into crack initiation sources at the strip edge under cold rolling and propagate toward the bulk of the rolled strip gradually. Inhomogeneous deformation and large secondary tensile stresses contribute to the initiation of microcracks. Fine-grain deposits tend to exhibit dislocation generation and movement and grain slide, thereby prohibiting crack initiation. ${ }^{[20]}$

To improve the ductility of steels, it is important to understand the mechanism of the edge crack initiation behavior. The porosity is a combination of primary porosity and secondary porosity, which affects formation performance significantly. Void growth plays a dominant role on crack initiation in regions with a high stress state ${ }^{[7]}$ The void nucleation parameters are related closely to the microstructural characteristics of the ferrite and pearlite steels. The grain boundary tends to affect the plastic deformation in the rolled strip, which could be a key factor that controls the crack retardation process at the boundary. A fine-grained structure gives better resistance to crack initiation because of the higher volume of grain boundary area per unit volume that resulted from grain refinement. ${ }^{[12]}$ Coarse-gained material shows a higher crack initiation rate than finegrained material owing to a much finer effect of microstructure such as grain boundaries and grain size. Grain-boundary strengthening takes effect because the grain boundaries act as barriers to plastic flow, dislocation sources, and additional stresses from elastic anisotropy. In addition, the grain refining process results in more homogenous deformation, ${ }^{[19]}$ which will postpone the crack initiation and increase the critical stress of crack initiation correspondingly. Therefore, grain size refinement can make crack initiation more difficult.

The grain size and grain boundary have a significant effect on edge cracking, and the density of microcracks increases with the grain size. Therefore, it is much easier to obtain crack initiation in ferritic rolled microstructures (coarse grain) than that in hot-rolled microstructures (fine grain). 


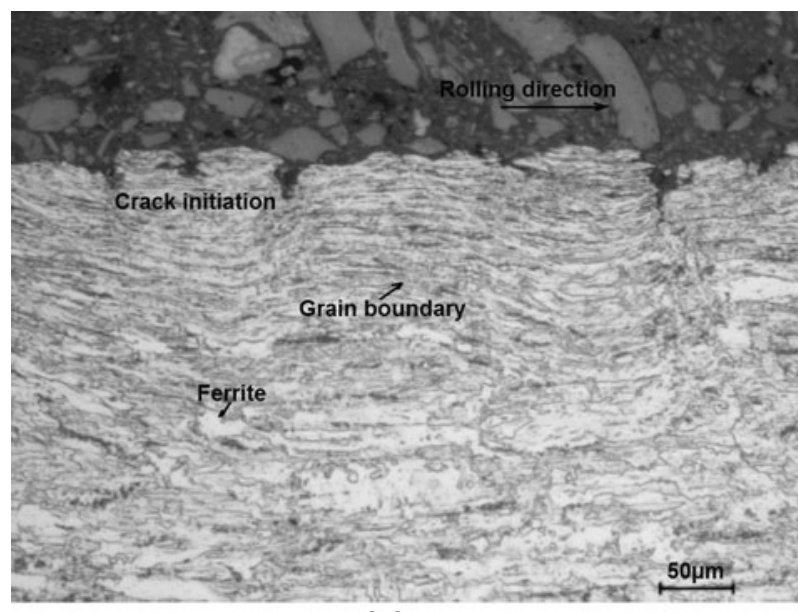

(a)

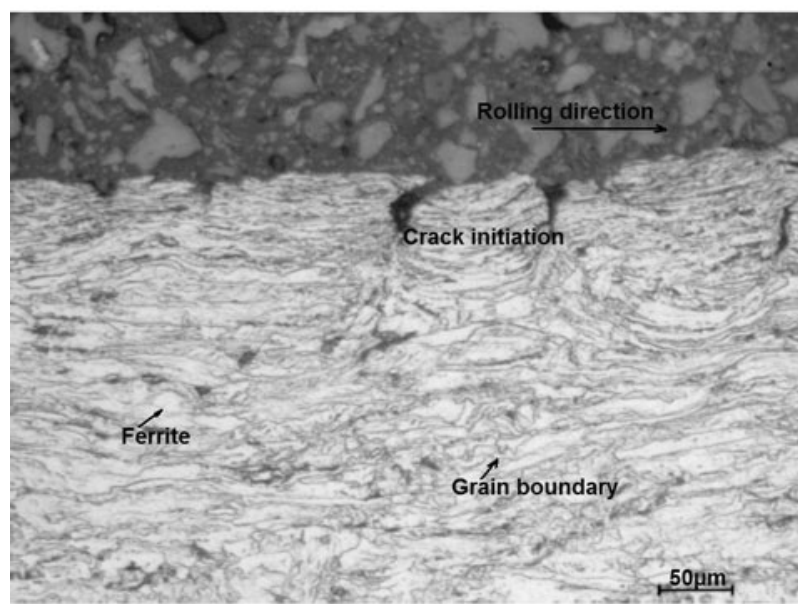

(b)

Fig. 2-Edge crack initiation in (a) coarse grain and (b) fine grain.

\section{Effect of Microstructure on Edge Crack Propagation}

Higher load levels lead to larger driving forces which allow small cracks to overcome microstructural barriers easily. Figure 3 shows the edge crack propagation during cold rolling of thin strip. Many pores or microvoids exist along the strip edge as shown in Figure 3(a). The edge cracks are located at an angle of approximately $45 \mathrm{deg}$ with respect to the rolling direction because of the shear stress being at its maximum at the localized shear planes at $45 \mathrm{deg}$ with respect to the rolling direction. ${ }^{[19]}$

Figures 3(b) and (c) show edge crack propagation for coarse grains (ferritic rolled microstructure) and fine grains (hot-rolled microstructure), respectively. It is obvious that the propagation of the edge crack is blunting near the crack tip in coarse grain, which represents approximately 75 pct of the tested samples in the experiment; in fine grain, the direction of propagation of the edge crack is more pointed and sharp near the crack tip, which constitutes approximately 85 pct of the tested samples. The blunted crack tip will reduce stress concentration during rolling, whereas the stress concentration will increase in the sharp crack tip in the

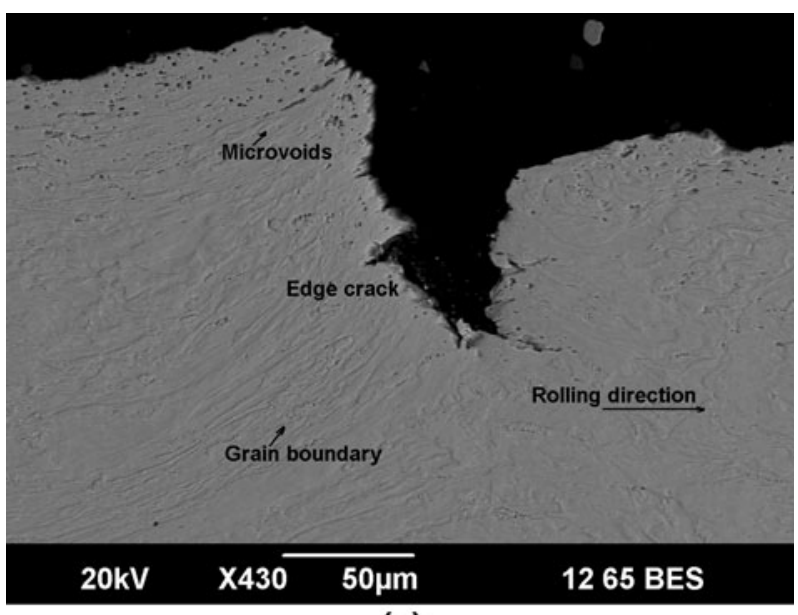

(a)

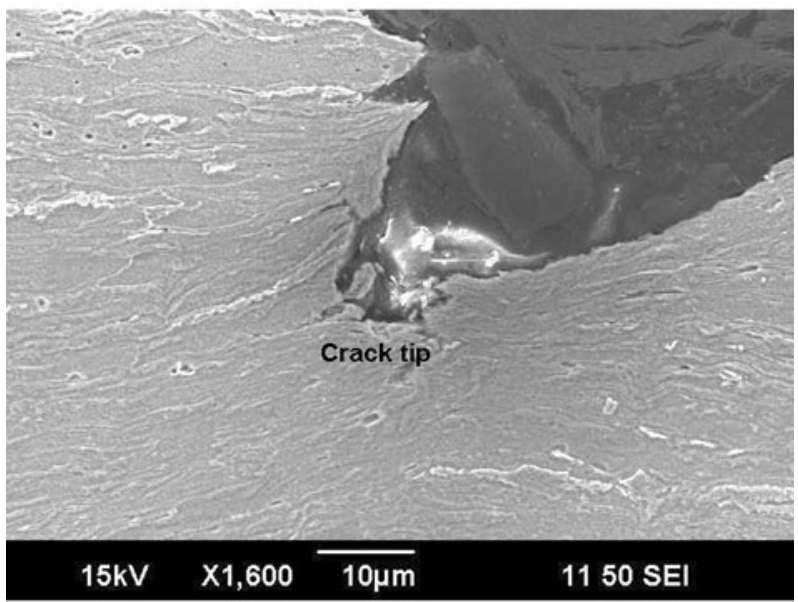

(b)

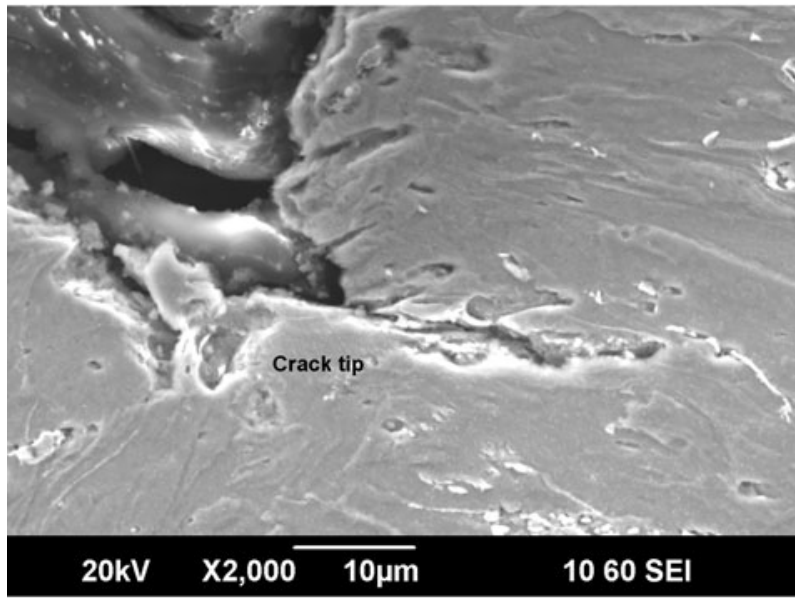

(c)

Fig. 3-(a) Edge crack propagation, (b) crack tip in coarse grain, and $(c)$ crack tip in fine grain.

hot-rolled microstructure and then accelerate the growth of edge cracks.

As discussed previously, the grain refinement should improve resistance to crack initiation in the rolled strip; however, such a beneficial effect becomes ineffective under higher applied stresses because of subsequent 


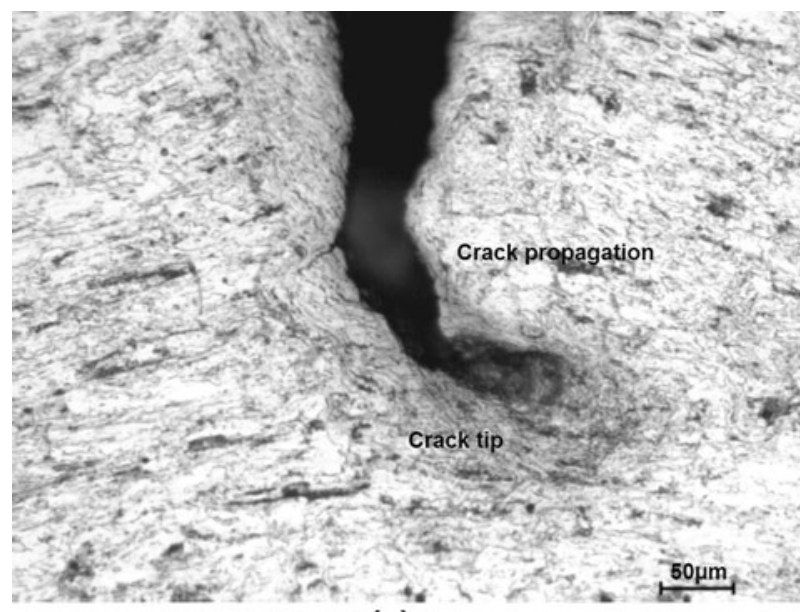

(a)

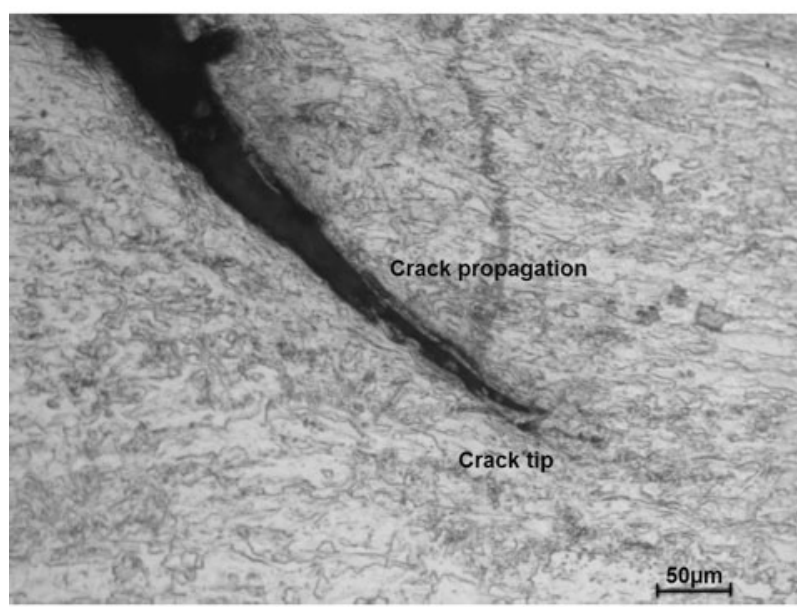

(b)

Fig. 4 - Crack propagation path in (a) coarse grain and (b) fine grain.

rolling passes. Then, the grain boundaries can be overcome more easily. Many microcracks exist in the coarse grain steel strip. Normally, the propagation of edge crack is a process of the competition among different multiple microcracks. ${ }^{[18]}$ Therefore, one of them becomes a dominant propagating crack, whereas the others become nonpropagating cracks. In this situation, the edge crack propagation will be decelerated by the occurring new cracks originating along strip edge, whereas some nonpropagation microcracks are found along the strip edge. Redistribution of edge stress will weaken stress concentration on the strip edge. Part of the energy is absorbed and the stress concentration at the microcrack tip decreases, and the prevention of propagation of the microcrack occurs in coarse grain strip. If the stress at this point is sufficient to drive the crack through adjacent grains, then the crack will propagate or the crack will be stopped at the boundary. In addition, the aspect of the elongated coarse grain is 0.75 before cold rolling, and the density of grain boundary becomes higher with subsequent rolling along the parallel direction to the rolling direction. The increase in density can retrain the edge crack propagation. ${ }^{[20]}$ Therefore, larger

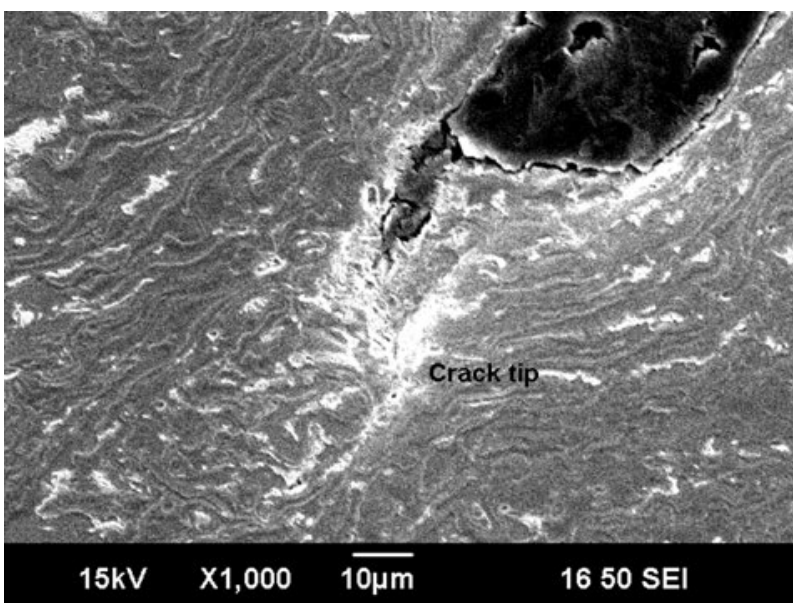

Fig. 5-Edge crack propagation during cold rolling.

elongated ferrite grain of ferritic rolled microstructure increases the crack growth resistance.

Figure 4 shows the different crack propagation path in coarse grain (Figure 4(a)) and fine grain (Figure 4(b)). It can be seen that the cracks in the coarse grain exhibit a more complicated path with more pronounced deflections and branching compared with those in the fine grain material. Therefore, the crack growth rate was reduced because of the complete change of the crack growth direction. In the fine microstructure, a less tortuous crack propagation path was observed compared with the coarse microstructure, and a relatively large crack extension rate was observed with the fine grain.

When the crack plane is perpendicular to these weak planes, crack tip blunting and stress reduction takes place, thus effectively toughening the material. ${ }^{[7]}$ This increase of toughness is attributed to an excessive blunting at the crack tip because of the presence of a high dislocation density. If two microstructures have the same constrained ductility and one blunts smoothly and the other shows sharper vertices, the microstructure that blunts the vertices can have substantially higher toughness.

No grain refinement effect occurs because once the strip is deformed to some extent or the total reduction reaches the critical value, the grain boundaries are obliterated. $^{[1]}$ Figure 5 shows the crack propagation during rolling, which includes the large amount of surface flow and the bending of the grains that have already been parted and now form part of the crack surface. This is the localization of flow within a plastic zone along characteristic directions, and the localization is affected by the activation of tangential velocity discontinuities along the characteristics. Local slip is concentrated at 45 deg from the crack plane.

\section{DISCUSSION}

\section{A. Stress and Crack Growth Analysis}

The stress and strain status between the center and the edge are shown in Figure 6 during cold rolling. It can be observed that the strip edge bears plane stress, whereas 
plane strain occurs in the strip center. The edges experience secondary tensile stresses because of the barrelling of the edge, which occurs as a fairly large tensile stress and in turn causes cracking. If bulging is observed at the edges, then the effect will be enhanced. Therefore, a tension stress is generated at the edges if ductility is low to make the length at the edge equal to that at the center. ${ }^{[16]}$

Figure 7 demonstrates schematically the process of crack propagation. It shows the formation and development of the typical fracture feature with cracks corresponding to the rolled microstructures. For most grains retaining a parallel laminated arrangement, micro cracks are formed first from the void growth along the transverse direction of the laminated weak interface ${ }^{[21]}$ during tensile deformation (Figure 7(a)). With an increase of tensile stress, the microcracks expand along the weak interface and some orientations, and the fracture boundary expands in the transverse direction. Subsequently, the crack tip meets the grain boundary, and the crack will extend into the other weaker (a)

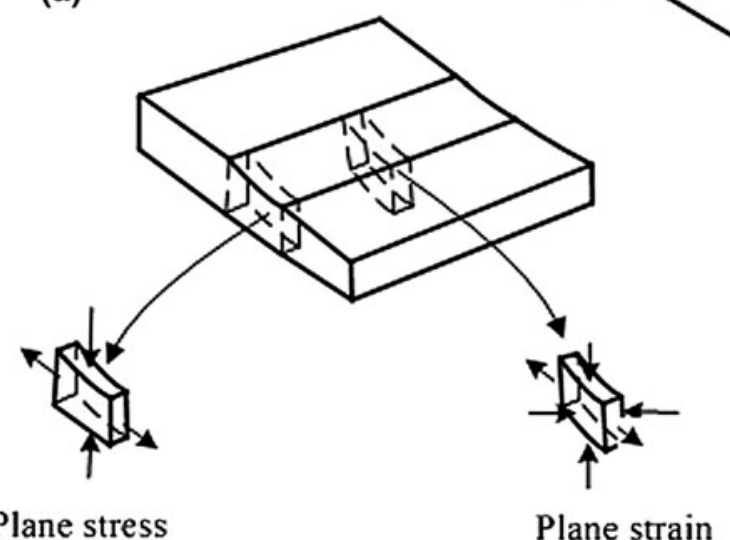

Fig. 6-The stress and strain status on the center and edge of the rolled strip $(a)$ and edge shape $(b)$. interfaces and orientations (Figure 7(b)). After this, the crack tip expands through the grains/grain boundaries with a subsequent increase in tensile stress, and the small crack changes into the localized delamination crack in the fracture region. Finally, the grains break and the dimples are formed between the local delamination cracks (Figure 7(c)).

\section{B. Crack Initiation}

It has been observed that finer grain size steels have higher fracture strengths than coarse-grained steels during crack initiation. ${ }^{[22]}$ Typically, fracture strength $\sigma_{f}$ is a function of the inverse square root of the grain size $d^{-1 / 2}$, which gives the dependence of grain size on crack initiation where the fracture stress has been determined. ${ }^{[23]}$ The fracture strength of a material, then, commonly obeys the following relationship with grain size, similar to the Hall-Petch equation:

$$
\sigma_{f}=\sigma_{0}+y k_{h p} d^{-1 / 2}
$$

where $k_{h p}$ is the slope representing the resistance against the slip propagation across a grain boundary, $\sigma_{0}$ is the frictional stress, $y$ is the coefficient, and $d$ is the average grain size.

The fracture strength $\sigma_{f}$ is derived from dislocation theory combined with the classical Griffith theory for a crack initiated around a dislocation pile-up at a grain boundary. When a crack size is larger than the grain size, it would lead to a slope lower than critical fracture toughness $K_{i c}$. In the coarse grain, the toughness starts at the single-crystalline value and rises to the polycrystalline value after it has traversed at least one grain. The peak stress at the crack tip increases with the reciprocal root of its size; the maximum size scales with $d$ and the effective grain size. Both the Griffith (energy) and Orowon (stress) criteria suggest that the fracture stress increases with grain refinement according to the HallPetch equation. ${ }^{[23]}$

The values of the fracture stresses calculated as a function of grain size are shown in Figure 8. It can be

RD
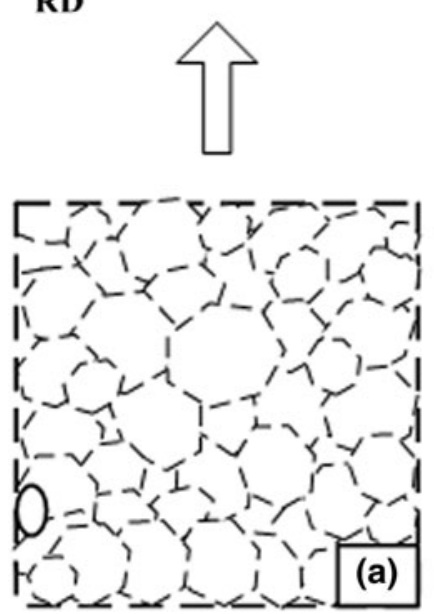
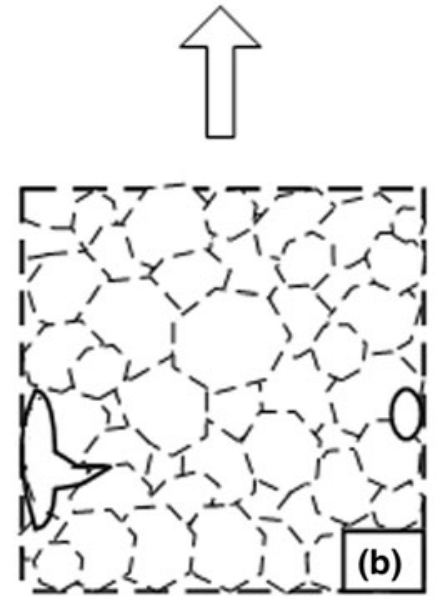
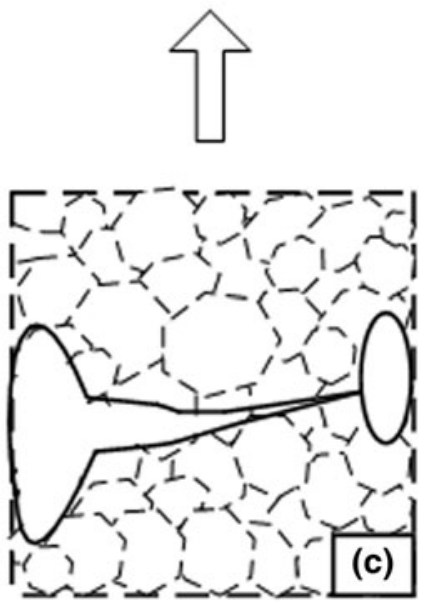

Fig. 7-The schematically process of crack propagation. 


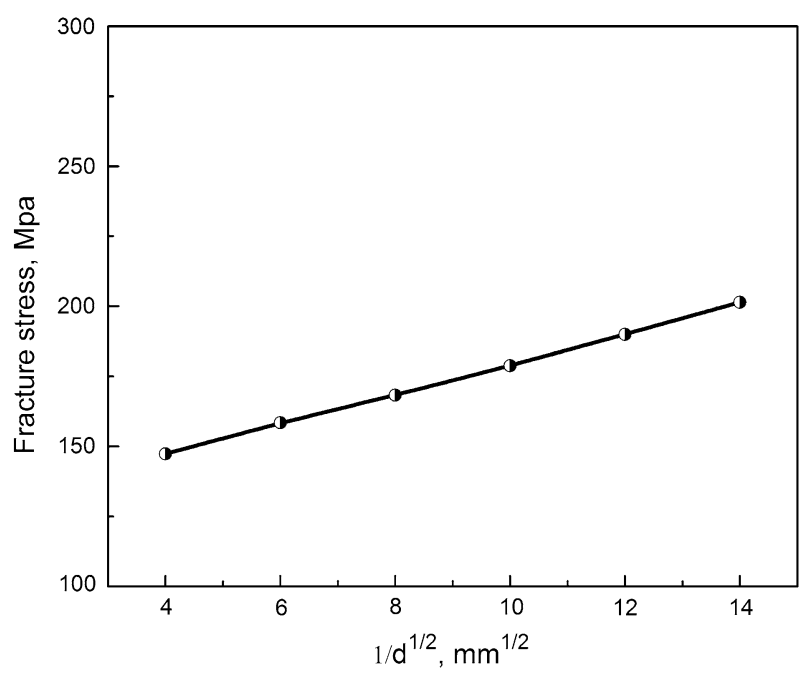

Fig. 8-Fracture strength with grain size.

seen that, over the range of grain sizes, the fracture stress varies linearly with the reciprocal square root of the ferrite grain size. The fracture strength increases with a decrease of grain size, which will postpone the edge crack initiation. Refinement of grain size both strengthens a material and improves its fracture toughness of crack initiation.

A similar expression has been developed that relates the fracture toughness $K_{c}$ to grain size by similar an inverse square root dependence. ${ }^{[23]}$

$$
K_{c}=C S^{1 / 2}\left[\sigma_{0}+k_{h p} d^{-1 / 2}\right]
$$

where $C$ is a constant of proportionality and $S$ is the width of the plastic process zone around the crack tip during crack initiation. The average grain size is a primary parameter that controls most of the important mechanical properties of the rolled strip.

Figure 9 shows the relationship between the fracture toughness and grain size. It can be observed that the fracture stress varies linearly with the reciprocal square root of the average grain size. Grain refinement can strengthen the crack initiation resistance. Fracture toughness changes from around $53 \mathrm{MPa}^{-1 / 2}$ to $89 \mathrm{MPa} \cdot \mathrm{m}^{-1 / 2}$ when the average grain size changes from $50 \mu \mathrm{m}$ to $5 \mu \mathrm{m}$. The higher the fracture toughness the more difficult is the crack initiation.

The experimental observations show no major edge cracking in low-carbon steel until a total reduction of approximately 85 pct is reached, which is in agreement with the results of References 7 and 24-26. The importance of the initial width-thickness ratio of the material on the onset of edge cracking is shown in Figure 10. The total cracking reduction acts as a function of the initial width-thickness ratio of the rolled strip for two frictional conditions: (1) lubricated rolling and (2) dry rolling. It can be observed that the total cracking reduction decreases with an increase of the width-thickness ratio. Thus, the edge cracks are easy to initiate in the strip edge with a large width-thickness ratio. The increase of the initial width-thickness will

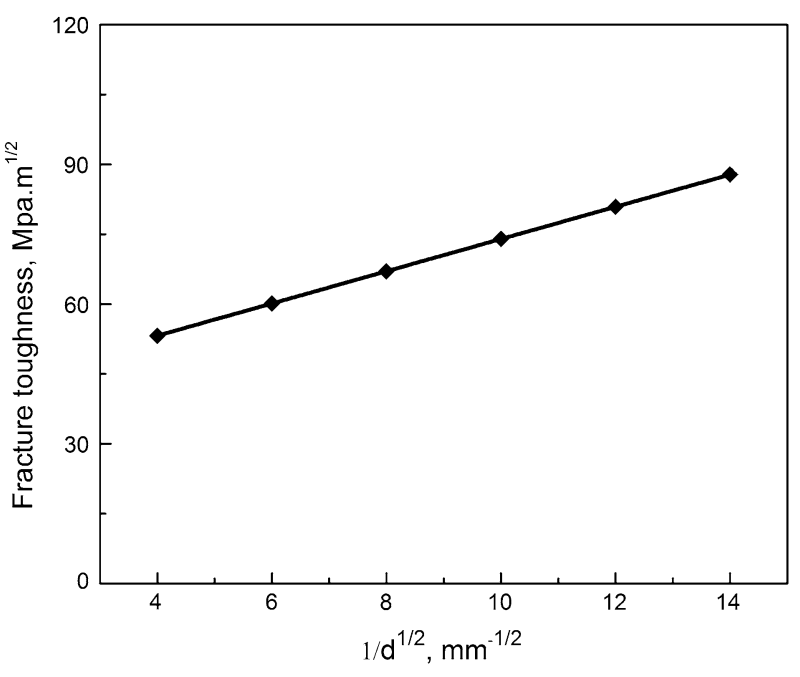

Fig. 9-Fracture toughness with grain size.

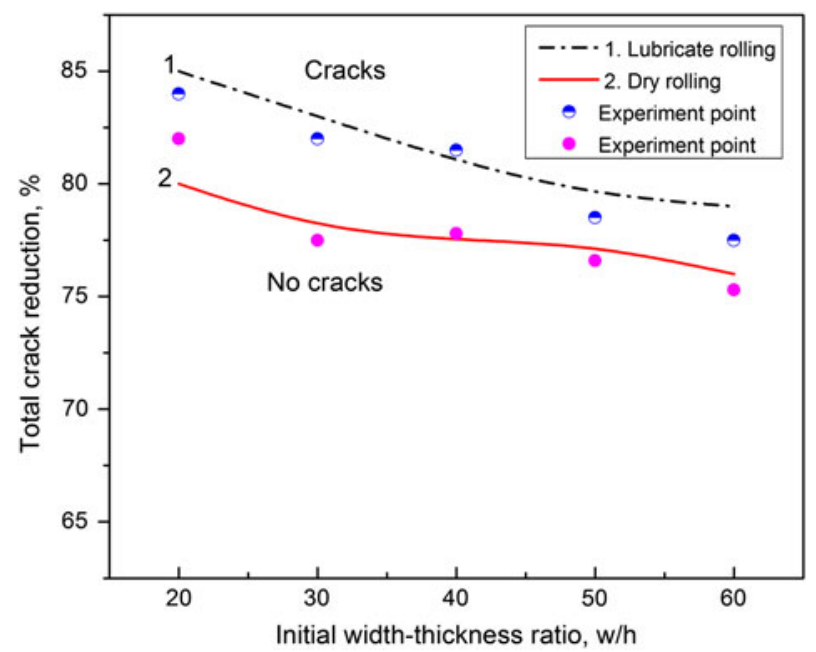

Fig. 10-Edge cracking reduction during cold rolling.

enlarge inhomogeneous deformation between the strip center and edge during cold rolling. This will cause crack initiation early. In addition, lubrication can improve the rolling conditions and increase the total cracking reduction.

\section{Crack Propagation}

A cohesive model can be used to describe the crack tip during cold rolling. Crack growth resistance in elastic plastic materials dominated by crack-tip plasticity is analyzed with the crack modeled as a cohesive zone. ${ }^{[27]}$ Cohesive traction acts all along this length of fracture process zone, as shown in Figure 11.

The area around edge crack is divided into four zones: inactive plastic zone, cohesive zone, active plastic zone, and elastic singularity zone. In addition, within the deformation region, the three subtips are as follows: physical crack tip, numerical crack tip, and mathematical crack tip. At point A, the material has separated completely and the traction has just 


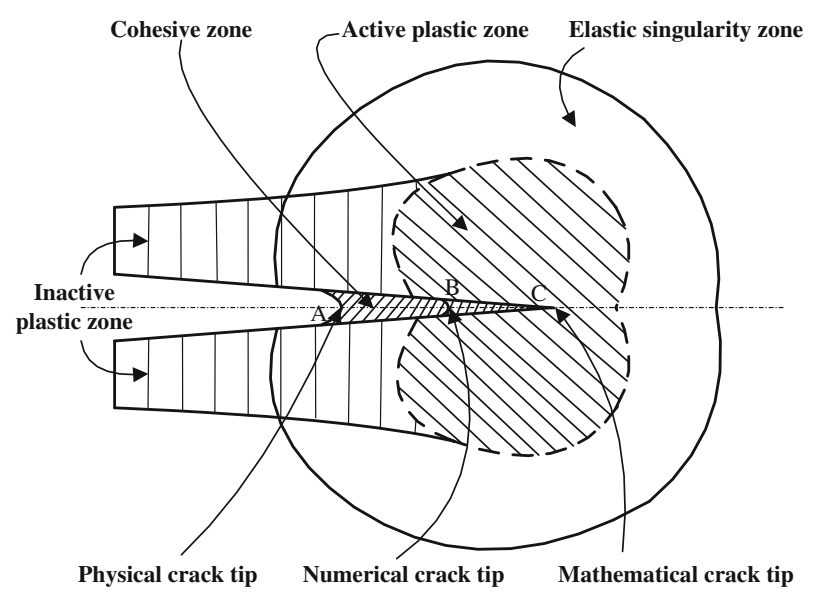

Fig. 11-Crack tip zone distribution.

vanished, representing the physical crack tip. Mathematically, crack tip can be assumed to be located at point $\mathrm{C}$ where no material separation takes place. From the physical perspective, the crack tip should be located at the point where the peak cohesive stress acts represented by point $\mathrm{B}$. The part of energy from point $\mathrm{C}$ up to point $\mathrm{B}$ is being spent in the area between $\mathrm{B}$ and $\mathrm{C}$.

The fracture process zone is typically embedded within the plastic zone. The local stresses ahead of the crack tip are sufficiently intense to rupture atomic bonds, and thus create a new free surface. Microcracking accelerates sufficiently to reduce the grain-boundary cohesion leading to crack propagation when the high tensile stresses act on the grain boundary plane. ${ }^{[27]}$ Consequently, cracks do not change their overall orientation when crossing former grain boundaries. The transformed zone, which develops in front of the crack tip, can be deviated from the direction perpendicular to the rolling direction when it meets the grain boundary. The increase of the stored energy after crack initiation indicates that the impingement of slip lines against grain boundaries continues during the crack growth stage.

Figure 12 shows the schematic illustration of the crack tip during numerical simulation. If the stress is insufficient, the crack will be stopped at the boundary, and become blunt into a ductile rupture void. Figure 13 shows the mean stress variation in relation to the distance to the crack tip around crack tip area. It can be observed that the mean stress increases with the distance to crack tip then decreases dramatically. The mean stress in fine grain is higher $(176 \mathrm{MPa})$ than that in coarse grain $(163 \mathrm{MPa})$ because of more stress concentration under various crack tip shapes. Therefore, the crack growth rate in fine grain is faster than that in coarse grain due to higher stresses during the subsequent rolling. The increase of the size of microstructure results in a decrease of the crack growth rate. In addition, this reduction in the crack growth rate was explained by a microstructure-dependent mode of crack growth that involved crystallographic bifurcation (i.e., the larger grain size permits larger bifurcation and thereby decreases crack growth rate). ${ }^{[28]}$

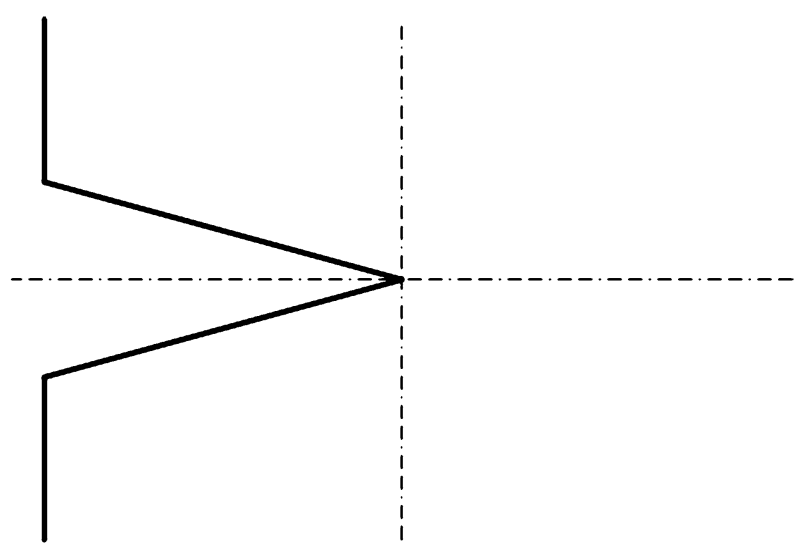

(a)

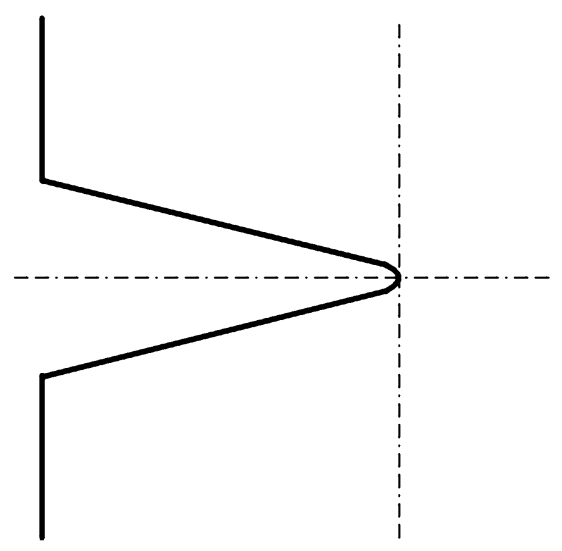

(b)

Fig. 12-Schematic illustration of (a) sharp crack tips (fine grain) and (b) blunted crack tip (coarse grain) in the numerical simulation.

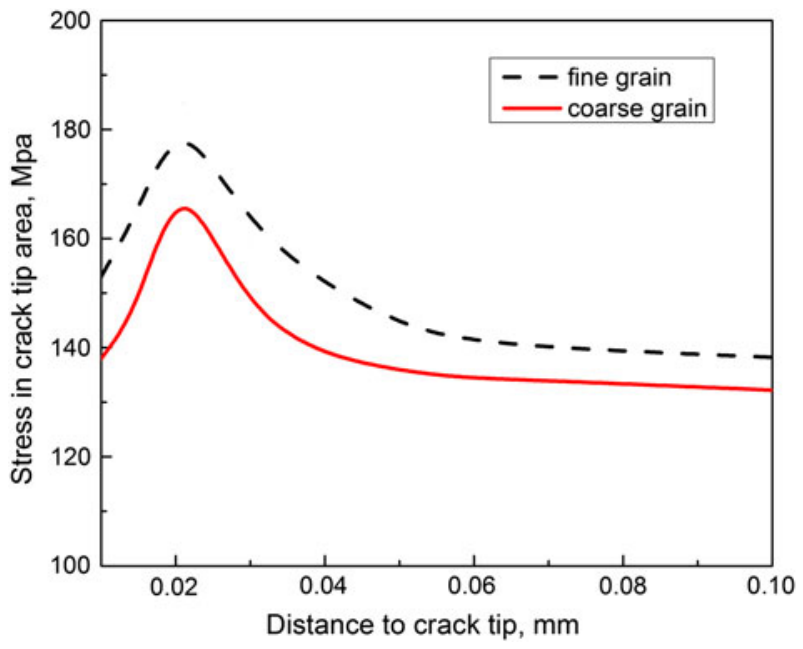

Fig. 13-Distribution of stress in crack.

\section{CONCLUSIONS}

The experimental research and mechanical analysis were carried out to investigate the microstructure 
influence on edge crack evolution of thin strip during cold rolling. The effects of initial microstructure on edge cracks were obtained.

This hot-rolled microstructure contains fine equiaxed ferrite and lameller pearlite, whereas ferritic rolled microstructure is composed of coarse elongated ferrite and pearlite. More microcracks exist in coarse grain than that in fine grain. The grain boundary is a barrier for edge crack initiation but does not prevent further deformation. The fracture strength increases linearly with the inverse square root of the mean grain size, and the proportional constant increases with strain. The fine microstructure has better resistance to crack initiation than the coarse microstructure. However, the coarse microstructure has a better resistance to crack propagation than that in the fine microstructure due to crack tip blunting. The crack growth rate decreases with an increase of grain size, and the large grain size develops greater crack growth resistance than the small grain size during crack propagation. The total cracking reduction decreases with an increase of the initial ratio of width and thickness. In addition, lubrication can delay the occurrence of edge cracking during cold strip rolling.

\section{ACKNOWLEDGMENTS}

The authors would like to thank BlueScope Steel Metallurgy Center for their seeding fund support for this research and thank Dr. Dongbin Wei, Mr. Joe Abbott, and Mr. T. Jacobson for their assistance in the experiments.

\section{REFERENCES}

1. H.C. Rogers: Acta Metall., 1959, vol. 7, pp. 750-52.

2. T. Zhai, A.J. Wilkinson, and J.W. Martin: Acta Mater., 2000, vol. 48, pp. 4917-27.
3. M.M. Al-Mousawi, A.M. Daragheh, S.K. Ghosh, and D.K. Harrison: J. Mater. Process. Tech., 1992, vol. 32, pp. 461-70.

4. C.L. Chow and J. Wang: Eng. Fract. Mech., 1987, vol. 21, pp. 54758.

5. T. Wierzbicki, Y.B. Bao, Y-W Lee, and Y.L. Bai: Int. J. Mech. Sci., 2005, vol. 47, pp. 719-43.

6. Y.D. Wang, H.B. Tian, A. Stoica, X.L. Wang, P.K. Liaw, and J.W. Richardson: Nat. Mater., 2003, vol. 2, pp. 101-06.

7. A. Dragon: Eng. Fract. Mech., 1985, vol. 21, pp. 875-85.

8. F. Ebrahimi and H.K. Seo: Acta Mater., 1996, vol. 44, pp. 831-43.

9. N. Ishikawa, D.M. Parks, and M. Kurihara: ISIJ Int., 2001, vol. 41 , pp. 76-85.

10. L. Zhen, Y.X. Cui, W.Z. Shao, and D.Z. Yang: Mater. Sci. Eng. $A$, 2002, vol. 336, pp. 135-42.

11. S. Daly, A. Miller, G. Ravichandran, and K. Bhattacharya: Acta Mater., 2007, vol. 55, pp. 6322-30.

12. F.C. Campbell: Elements of Metallurgy and Engineering Alloys, ASM International, Materials Park, OH, 2008, pp. 120-25.

13. H. Kametani: Metall. Mater. Trans. B, 1998, vol. 29B, pp. 126167.

14. J. Konishi, M. Milizer, J.K. Brimacombe, and I.V. Samarasekera: Metall. Mater. Trans. B, 2002, vol. 33B, pp. 413-23.

15. F. Czetinski, A. Brodtka, J.Y. Cho, A. Zielinska-Lipiec, J.H. Sunwoo, and J.A. Szpunar: Scripta Mater., 1997, vol. 37, pp. 1231-35.

16. M.H. Han, S. Lee, N.J. Kim, K.J. Lee, T. Chung, and G. Byun: Mater. Sci. Eng. A, 1999, vol. 264, pp. 47-59.

17. H. Riedel, F. Andrieux, T. Walde, and K.-F. Karhausen: Steel Res. Int., 2007, vol. 78, pp. 818-24.

18. P.F. Thomson and N.M. Burman: Mater. Sci. Eng., 1980, vol. 45, pp. 95-107.

19. N. Narasaiah and K.K. Ray: Mater. Sci. Eng. A, 2005, vol. 392, pp. 269-77.

20. H. Somekawa, T. Inoue, and T. Mukai: Mater. Sci. Eng. A, 2010, vol. 527 , pp. $1761-68$

21. Y. Nakai and K. Tanaka: Eng. Fract. Mech., 1961, vol. 15, pp. 291-302.

22. F. Yuan and K. Hayashi: Wear, 1999, vols. 225-229, pp. 83-89.

23. M. Li and F. Guiu: Acta Metall. Mater., 1995, vol. 43, pp. 185969.

24. D.A. Curry and J.F. Knott: Met. Sci., 1976, vol. 1, pp. 1-6.

25. C. Mercer and W.O. Soboyejo: Scripta Mater., 1996, vol. 35, pp. $17-22$.

26. Z.H.J. Gu and W.Y.D. Yuen: Proc. SEAISI2007 Conference 2007, Session 12, Paper 1, Bali, Indonesia, 2007.

27. H. Li and N. Chandra: Int. J. Plast., 2003, vol. 19, pp. 849-82.

28. S. Mall, S.A. Namjoshi, and W.J. Porter: Mater. Sci. Eng. A, 2004, vol. 383 , pp. $334-40$. 